\title{
Probing the origins, diagnosis and treatment of amyloid diseases using antibodies
}

\author{
Mireille Dumoulin *, Christopher M. Dobson \\ Department of Chemistry, University of Cambridge, Lensfield Road, CB2 1EW Cambridge, UK \\ Received 6 April 2004; received in revised form 12 July 2004; accepted 16 September 2004 \\ Available online 19 October 2004
}

\begin{abstract}
The deposition of proteins in the form of amyloid fibrils is the characteristic feature of more than 20 medical conditions affecting the central nervous system or a variety of peripheral tissues. These disorders, which include Alzheimer's disease, the prion diseases and type II diabetes, are of enormous importance in the context of present-day human health and welfare. Extensive research is therefore being carried out to define the molecular details of the mechanism of the pathological conversion of amyloidogenic proteins from their soluble forms into fibrillar structures. This review focuses on recent studies that demonstrate the power of using antibodies or antibody fragments to probe the process of fibril formation, and discusses the emerging potential of these species as diagnostic and therapeutic agents.
\end{abstract}

(C) 2004 Elsevier SAS. All rights reserved.

Keywords: Antibodies and antibody fragments; Protein misfolding; Protein aggregation; Amyloid diseases; Diagnostic and therapeutic strategies

\section{Introduction}

Proteins are the major molecular components of cells and are involved in virtually every biological process taking place in living systems. In a cell, proteins are synthesised on ribosomes as linear polymers containing 20 different types of amino acids linked together in a specific order by covalent peptide bonds to form a polypeptide chain. Although most proteins need to fold into unique, compact three dimensional structures (generally referred to as their native states) to acquire their functionality, unfolded or partially folded states of proteins are important in events such as translocation

Abbreviations: A $\beta$, beta-amyloid peptide; ADDLs, A $\beta$-derived diffusible ligands; AFM, atomic force microscopy; BSE, bovine spongiform encephalopathy; cAb-HuL6, a camel antibody fragment raised against wild type human lysozyme; FTIR, Fourier transform infrared; IAPP, islet amyloid peptide; NMR, nuclear magnetic resonance; $\mathrm{PrP}$, the prion protein, $\operatorname{PrP}^{\mathrm{C}}$, the normal cellular form of the prion protein; $\mathrm{PrP}^{\mathrm{Sc}}$, the pathogenic scrapie form of the prion protein; TEM, transmission electron microscopy; TTR, transthyretin; vCJD, variant Creutzfeldt-Jakob disease; $\mathrm{V}_{\mathrm{H}} \mathrm{H}$, the variable region of a camelid heavy-chain antibody.

* Corresponding author. Tel.: +44-12-2376-3845; fax: +44-12-2376-3849.

E-mail address: mmjd3@cam.ac.uk (M. Dumoulin). across membranes and trafficking to specific cellular locations [1]. Moreover, in recent years, increasing numbers of proteins have been found to be intrinsically unstructured [2]. These proteins, that have little or no secondary or tertiary structure under physiological conditions in the absence of their natural ligands or partners, appear to be important in the regulation of a number of key cellular processes [2]. For the large majority of protein molecules, however, efficient and accurate folding is crucial for maintaining their proper functions in all cellular processes. Nature has, therefore, developed a series of strategies to ensure that proteins fold, and remain properly folded, where and when they are required. These strategies include the evolution of specific polypeptide sequences, the involvement of folding catalysts and molecular chaperones, and the development of sophisticated quality control mechanisms [3-5].

Under some circumstances, however, despite these safeguards, proteins can fail to achieve their functional structures with consequences that can be extremely serious, including the onset of pathological and often fatal disorders. Some of these disorders, which include cystic fibrosis and emphysema among others, result from proteins folding incorrectly and thus not being able to reach their appropriate destination or exercise their proper function(s) [6]. In other cases, proteins with a high propensity to misfold escape all the above 
mentioned protective mechanisms and assemble into large aggregates that can be highly organised and be extremely stable. Amyloidoses, in which proteins assemble into amyloid fibrils (Textbox 1), belong to this latter family of disorders that are associated with polypeptide aggregation. The list of diseases found to be associated with amyloid deposition keeps growing. More than 20 different human amyloid disorders are known so far, and include Alzheimer's disease, the spongiform encephalopathies and type II diabetes $[7,8]$. In each of these pathological conditions, a specific protein or protein fragment (for example, the $A \beta$-peptide in Alzheimer's disease, the prion peptide in the spongiform encephalopathies or the islet amyloid polypeptide in type II diabetes) converts from its normal soluble state into insoluble amyloid fibrils which accumulate in a variety of organs and tissues (for recent reviews see [7,9]). These diseases that can be sporadic, inherited or even transmissible, are often hard to diagnose and are in most cases incurable, frequently leading to premature death. They are often manifest late in life and inflict enormous psycho-sociological and economic burdens in western societies [10]. In 2000, for example, there were 4.5 million persons with Alzheimer's disease in the US population, and by 2050 this number could increase by almost threefold to 13.2 million [11]. Extensive research is therefore being carried out to tackle the prevention and treatment of these diseases. To achieve this aim, it is crucial to understand the mechanism and molecular details of the pathological conversion of amyloidogenic proteins into fibrillar structures.

\subsection{The generic nature of the amyloid structure}

Until very recently it was thought that only a small number of polypeptide chains associated with clinical disorders were able to form amyloid fibrils. A number of recent studies has, however, shown that proteins unrelated to diseases, under suitable conditions, can form aggregates in vitro with structural and cytotoxic properties that closely resemble those of the amyloid fibrils that are formed in diseased tissues [12-15]. These observations have led to the hypothesis that the ability to form amyloid structures is a generic property of proteins resulting from stable interactions primarily involving the main chain that is common to all polypeptides $[5,16]$. Despite the variations in amino acid sequences and native folds when proteins form amyloid fibrils, they all adopt the cross- $\beta$-sheet structure that is the hallmark of these structures [17]. It is therefore evident that major conformational rearrangements are usually required for the formation of amyloid structures. Our current understanding of the events leading to the transformation of a soluble protein into insoluble amyloid fibrils is illustrated in Fig. 1. According to this picture, the conversion process can be schematically divided into two steps. The first consists of a conformational change leading to the formation of an ensemble of species competent for self-association, often referred to as amyloidogenic intermediate(s) (black box in Fig. 1). In such species, the peptide or protein involved exposes at least part of its main chain and hydrophobic residues to the solvent under conditions in which intermolecular interactions can take place. In the case

\section{Textbox 1 \\ Amyloid fibrils \\ "Amyloid" is a generic term that refers to aggregates organized in a cross $-\beta$ structure, with specific tinctorial properties and a fibrillar appearance. It was originally used to refer to the protein deposits that accumulate extracellularly in vivo into plaques. The use of the term "amyloid" is now frequently used to include intracellular aggregates that exhibit similar structural, morphological and tinctorial properties, for example those found in Parkinson's and Hungtingtn's disease, and to fibrils made in vitro from proteins not associated with disease.}

\section{A fibrillar appearance}

After negative staining with uranyl acetate, mature fibrils typically appear as unbranched structures, $\sim 100 \AA$ in diameter and of indefinite length (often above $1 \mu \mathrm{m}$ ) in the electron microscope. The exact morphology of the fibrils, corresponding to variations on a common theme, are usually dependent on the conditions used for their formation as well as the specific nature of the polypeptide sequence involved.

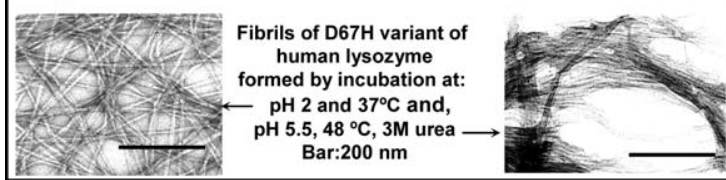

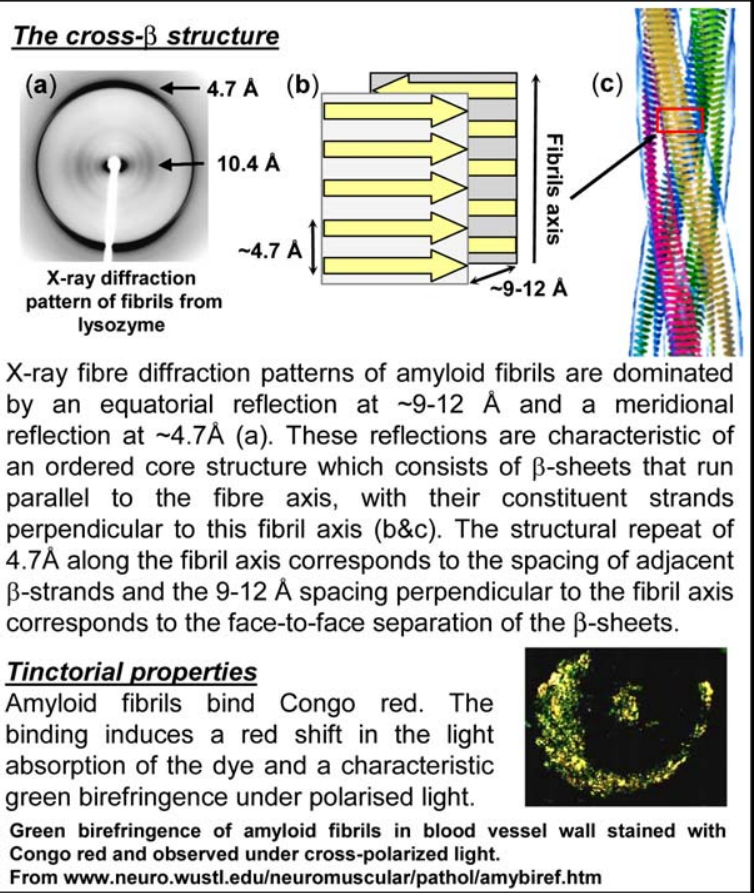




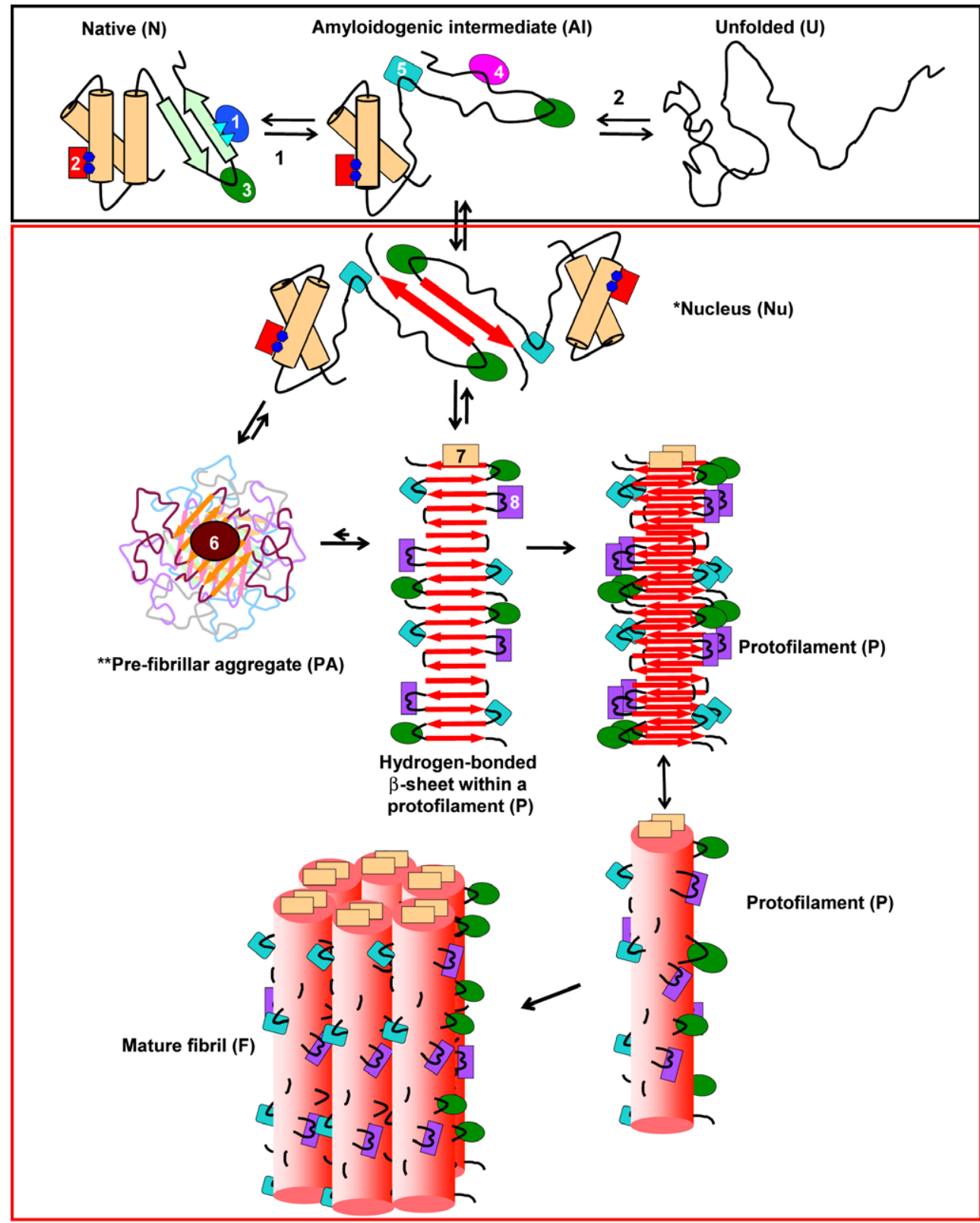

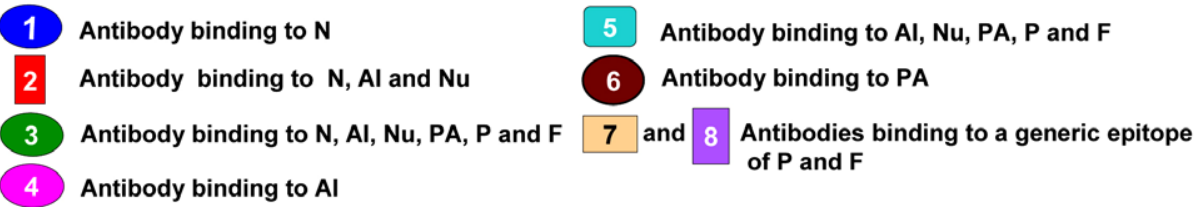

Fig. 1. Schematic representation of the mechanism of formation of amyloid fibrils and the various types of antibodies that can be produced. The first step in the process of formation of an amyloid fibril (black box) is the formation of an amyloidogenic intermediate via the partial unfolding of the native state (arrow 1) or via partial folding of otherwise naturally unfolded species (arrow 2). The second step is the self-association of the amyloidogenic intermediates, which eventually leads to the formation of amyloid fibrils (red box). The amyloidogenic intermediates have a high tendency to aggregate and become stabilised by the formation of intermolecular $\beta$-sheets. Small oligomers are formed initially that act as nuclei to direct the further growth of aggregates (*Here the nucleus is for simplicity shown as a dimer). This growth leads to the formation of higher order oligomers referred to as pre-fibrillar aggregates (PA, sometimes also referred to as amorphous aggregates, micelles or protofibrils). These aggregates convert into protofilaments (P) directly or indirectly, and finally into mature fibrils (F). Such fibrils usually consist of two to six protofilaments that are often twisted around each other to form a rope-like structure as shown in Box 1c. (**According to this scheme, antibodies 3 and 5 also bind to PA species but they are not represented for clarity).

of globular proteins, the formation of amyloidogenic intermediates involves the disruption of the native structure to a greater or lesser extent [18-20]; in natively unfolded proteins or unstructured peptides, this step may involve the formation of partially folded species with a high propensity to aggregate $[21,22]$. The second step is the self-association of the 
amyloidogenic intermediates, which eventually leads to the formation of amyloid fibrils (red box in Fig. 1). There is growing evidence, based on studies of various diseaserelated and disease-unrelated proteins that the aggregation process is complex, generally following a nucleation/ polymerisation mechanism [23] and involving a variety of conformational rearrangements and multiple steps of assembly (for reviews see $[7,24]$ ).

The investigation at an atomic level of the structures of the species involved in the formation of amyloid fibrils, and the understanding of the mechanism of the assembly process is technically extremely challenging. First, fibril formation in vivo usually takes place over a period of several years. In order to carry out detailed studies of such processes in vitro, it is therefore necessary to increase considerably the rates at which they occur. For globular proteins, one way of achieving this objective is to employ conditions that favour the formation of at least partially unfolded states, for example low $\mathrm{pH}$ values [25], high temperatures [26], low to moderate concentrations of strong denaturants [27,28], or the presence of organic solvents $[13,29]$. Second, the structural characterisation of the various species formed during the process of fibril formation is complicated by their heterogeneity and by their transient or insoluble nature. For example, it is difficult to maintain the species that represent the precursors to high molecular weight aggregates at the high protein concentrations required for NMR studies without extensive aggregation. In addition, the partially unfolded, and hence disordered, nature of these species makes it unlikely that they will by themselves crystallise to allow high resolution X-ray crystallographic experiments to be carried out. The determination of detailed structures of the mature fibrils is also challenging due to their intractable and frequently heterogeneous nature, which again seriously limits the application of the traditional methods of structural biology such as solution NMR spectroscopy and X-ray diffraction techniques. Structural information concerning amyloid fibrils has, however, been obtained from atomic force microscopy (AFM) [30,31], FTIR [32,33], X-ray fibre diffraction studies [17], cryoelectron microscopy [34,35], hydrogen/deuterium exchange analysed by mass spectrometry and NMR [36-39] and solid state NMR [40,41]. Important information about both the structures of the aggregates and the mechanism of their formation has also been obtained by using methods such as limited proteolysis [42,43], systematic site-directed mutagenesis [44-46], and the analysis of the effects of interactions with specific antibodies. In this review, we focus on the latter technique and show through examples how the use of antibodies, or antibody fragments, can provide unique information concerning the nature of the different steps in amyloid fibril formation described above. In addition we discuss how such species can form the basis for novel strategies to diagnose and treat diseases associated with amyloid formation.

\section{Structural probes}

\subsection{Probes of the structural features of amyloidogenic intermediates}

Antibodies can be used in several ways to investigate the structural differences existing between an amyloidogenic intermediate and the native state of a protein of interest. One of these ways is to generate antibodies against diverse epitopes of the native protein (antibodies 1-3 in Fig. 1) and then to compare their binding properties before and after the conformational changes that result in the formation of amyloidogenic intermediates [47]. The region(s) of the protein where such changes occur, and those where the native structure is conserved, can then be mapped, at least in outline. Moreover, as partial unfolding is likely to result in the exposure of regions of a protein that are normally buried within the native fold, antibodies raised against epitopes located in such regions (antibodies 4 and 5 in Fig. 1) will recognise amyloidogenic intermediates but not the native conformation of the protein. Such an approach can therefore provide information about the structure that is adopted by the region of the protein involved in the unfolding event. In addition, antibodies or antibody fragments specific to amyloidogenic intermediates are of particular interest because such species have been used successfully to co-crystallise unstable or insoluble proteins [48-50]. Such an approach might therefore provide a unique opportunity to obtain the X-ray structure of an amyloidogenic intermediate. The generation of appropriate antibodies can, however, be challenging because in many cases the amyloidogenic intermediates are only significantly populated under highly destabilising conditions (i.e. high temperature or in the presence of denaturants) that are incompatible with the immunisation procedures required to generate antibodies.

One way to circumvent this particular problem is to generate mutant proteins that are destabilised sufficiently to allow the formation of intermediate species under physiological conditions. For example, a mutant of transthyretin (TTR) has been constructed that has a structure thought to represent the partially misfolded conformation of the precursor for amyloid formation [51]. Through the generation of monoclonal antibodies against this mutant protein, two epitopes have been found that become exposed in the amyloidogenic intermediate of TTR. On this evidence, it has been suggested that the partial denaturation of the strands C and D of TTR, which encompass these epitopes, is a prerequisite to self-aggregation. Another way of generating antibodies against amyloidogenic intermediates is to design, on the basis of available biophysical and biochemical data concerning the amyloidogenic intermediate, peptides that will "mimic" structural features of this species, and then to use such peptides for immunisation. This latter strategy has been used to generate both polyclonal and monoclonal antibodies specific to the pathogenic scrapie form of the prion protein $\left(\mathrm{PrP}^{\mathrm{Sc}}\right)[52,53]$. Using a combination of these approaches, a 
range of recombinant antibodies has been generated and used to map the conformational changes associated with the formation of $\operatorname{PrP}^{\mathrm{Sc}}$ [47,52-57] or to probe the conformation of the normal cellular form of the prion protein $\left(\operatorname{PrP}^{\mathrm{C}}\right)$ on the cell-surface [58].

\subsection{Probes of structural features of soluble aggregates}

A considerable body of experimental evidence suggests that the Alzheimer peptide $(\mathrm{A} \beta)$ under certain conditions exists in the form of soluble spherical oligomers, which are often described as "protein micelles" or "A $\beta$-derived diffusible ligands (ADDLs)" (for recent reviews see $[59,60]$ ). Based on this evidence, Kayed et al. [61] generated a molecular mimic in which the $\mathrm{C}$-terminus of the $\mathrm{A} \beta_{1-40}$ peptide was covalently linked to gold particles. The mimic displayed many of the physical properties of ADDLs, but was significantly more stable and therefore could be used as an antigen against which to raise antibodies. Antibodies generated in this way (antibody 6 in Fig. 1) were found to recognise $\mathrm{A} \beta$-oligomers with a specific range of sizes, but not monomeric $A \beta$ or $A \beta$-fibrils. The antibodies appear to bind both the spherical oligomers that are populated at the early stages of the $\mathrm{A} \beta$ aggregation process and the elongated protofibrillar species that are formed later in the aggregation process. These observations suggest that both spherical and protofibrillar species have at least some structural properties in common. Most remarkably, however, these antibodies also appear to recognise specific soluble oligomers derived from other types of amyloidogenic peptides and proteins, e.g. the prion peptide fragment 106-136, islet amyloid polypeptide, lysozyme, human insulin, and $\alpha$-synuclein [61]. This finding suggests that the soluble oligomers from different proteins have some common characteristic conformational features regardless of the sequence of the protein that they are derived from. This common structural motif is therefore likely to be based on the peptide backbone rather than on the particular amino acid side chains.

\subsection{Probes of structural features of mature fibrils}

In some cases, it is likely that only certain segments of a polypeptide chain will be involved in the structural core of the fibrils with the remainder of the chain being organised in some other manner at the surface of the amyloid fibril [62]. In other cases, it is probable that most of the polypeptide chain is involved in the core of the fibril, as for example in the case of relatively short peptides [63]. These observations raise the general questions of which portions of a polypeptide sequence are in the cross- $\beta$ core structure, and of which structure is adopted in regions that are not involved in this core. Studies of antibody binding can provide clues for the answers to such questions. Antibodies specific to the N-terminal sequence of $A \beta$-peptide have been found to inhibit in vitro aggregation and stimulate the disassembly of preformed fibrils leading to the inhibition of their cytotoxicity [64-67].
The mechanism by which these antibodies act is not yet clear, but one possibility is that the N-terminal amino acids of $A \beta$ are accessible when the peptide is both in its monomeric and its aggregated form; thus antibodies that are directed against this region can both inhibit fibril formation and induce fibril dissociation." This finding is in good agreement with the structural model of A $\beta$-fibrils derived from solid state NMR which suggest that the eight $\mathrm{N}$-terminal residues are not involved in the core structure of the amyloid fibrils [68]. Similarly, antibody binding studies have suggested that the regions corresponding to the residues 27-37 and 101-111 of $\alpha$-synuclein are exposed to the external environment in the aggregated fibrillar form of this protein [69].

Recently, monoclonal antibodies that have been produced against $A \beta$-fibrils have been found to bind to amyloid fibrils derived from a variety of proteins, such as TTR, IAPP, $\beta 2-$ microglobulin, and polyglutamine [70] (antibodies 7 and 8 in Fig. 1). These antibodies do not, however, bind to the soluble precursors of these fibrils, nor do they bind to other forms of protein aggregates such as bovine collagen, elastin or gelatin. In addition, a monoclonal antibody raised against amyloid proteins extracted from spleens and livers of patients with immunoglobulin light chain-associated amyloidosis, has been reported to recognise ex vivo amyloid fibrils composed of the light chain variable domain, $\mathrm{A} \beta$, and other amyloidogenic proteins [71].

These results suggest that these antibodies recognise a conformational epitope that is characteristic of amyloid fibrils rather than specific polypeptide sequences. One possible contributor to a common amyloid structural epitope might be a unique array of hydrogen-bond donor and acceptor groups from the polypeptide backbone at the edge strands of the $\beta$-sheets of the ends of amyloid fibrils (antibody 7 in Fig. 1) [70]. Another possibility is that the main chain is involved in some unusual turn or chain reversal within the amyloid structure (antibody 8 in Fig. 1) [70,72].

Definition of the generic conformational epitope(s) of amyloid fibrils will undoubtedly give unique information about the essential elements of the fibrillar structure. The task of defining the epitopes is, however, challenging because techniques that are usually employed to identify the detailed structures of conformational epitopes of anti-protein antibodies, such as X-ray crystallography, solution NMR or differential chemical modification cannot be easily applied to amyloid fibrils $[70,73]$.

\section{Probes of the mechanism of amyloid fibril formation}

In addition to enabling the study of the structures of the various species formed during fibril formation, antibodies can also be used to obtain mechanistic information concerning the sequence of events leading to the formation of amyloid fibrils and probe the toxicity of the various species involved. 


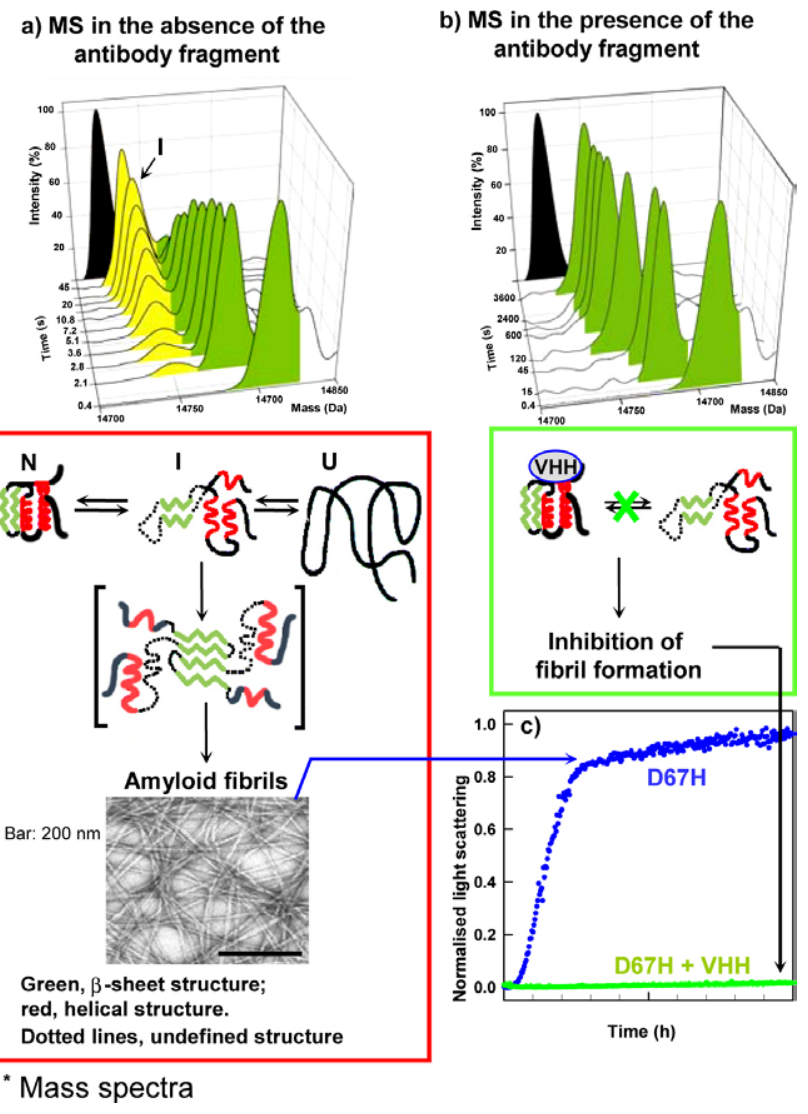

Fig. 2. Probing human lysozyme amyloid formation and inhibition using a camel antibody fragment. Four single-point mutants (I56T, F57I, D67H and W64R) and a double mutation (F57I/T70N) of human lysozyme are associated with systemic amyloid disease [114-116]. The effects of the D67H mutation on the properties of the lysozyme molecule have been studied at the molecular level using a variety of techniques including pulse labelling hydrogen/deuterium exchange analysed by mass spectrometry and NMR spectroscopy $[28,117]$. In the electrospray mass spectra of the D67H variant pulse labelled in the absence of the antibody fragment, two peaks are observed (Panel a), whereas the spectrum of the wild type protein under similar conditions shows a single peak [117]. The additional peak (coloured in yellow) has been shown to result from a locally cooperative unfolding event, identified as the unfolding of the $\beta$-domain and the C-helix of the variant protein molecule [117]. From this result, and those of previous studies [18,117,118], a mechanism of fibril formation has been proposed for lysozyme (red box). As a result of its reduced stability and global cooperativity, the D67H variant protein populates transiently a partially unfolded intermediate (species I) in which the three helices that form the core of the $\alpha$-domain still have native-like structure, whereas the $\beta$-domain and the $\mathrm{C}$-helix are substantially disordered. The formation of intermolecular interactions between molecules in this intermediate state is likely to be the origin of the aggregation events that ultimately lead to the formation of amyloid fibrils. In the electrospray mass spectra of the $\mathrm{D} 67 \mathrm{H}$ variant pulse labelled in the presence of a camelid antibody fragment, cAb-HuL6, raised against wild type human lysozyme, the $\mathrm{D} 67 \mathrm{H}$ variant protein appears as a single peak (Panel b). This result indicates that the locally cooperative unfolding event observed for the lysozyme variant has been suppressed by the presence of the antibody fragment (green box). The binding of the antibody fragment, therefore, restores the stability and the cooperativity characteristic of the wild type protein. Thus, the result of antibody binding is to prevent the ready conversion of the lysozyme variants into their aggregated states (Panel c). These results strongly support the involvement of at least transient partially unfolded species in the initiation of the aggregation events that lead to the formation of amyloid fibrils by globular proteins. NMR and X-ray structural analyses of the complex have suggested a specific mechanism by which the

\subsection{Elucidation of misfolding events}

It has been shown that appropriate monoclonal antibodies can inhibit the aggregation of amyloidogenic peptides and proteins by binding to them in their soluble forms. Antibodies could mediate their inhibitory effect by directly binding to the regions of a peptide or a protein where the conformational changes or the aggregation processes are initiated [64,74]. It has been shown, however, that they can also act through a more subtle mechanism [28]. Thus, we have recently reported that a single-domain fragment of a camelid antibody $\left(\mathrm{V}_{\mathrm{H}} \mathrm{H}\right)$ raised against wild type human lysozyme inhibits the in vitro aggregation of its amyloidogenic variant, $\mathrm{D} 67 \mathrm{H}$ (Fig. 2). This inhibition was found to result from the stabilisation of the native state of the protein, thereby preventing the conformational changes that lead to the formation of the amyloidogenic intermediate and thus its conversion into amyloid fibrils. Remarkably, structural studies reveal that in the lysozyme case, the epitope includes neither the site of mutation nor most residues located in the region of the protein structure that is destabilised by the mutation. Thus, the effects of the binding of the antibody fragment are not simply to mask the entire region of the protein destabilised by the mutation and hence prevent its unfolding from the remainder of the structure. Instead, the binding of the antibody fragment achieves its effect by restoring the structural cooperativity characteristic of the wild type protein that is lost as the result of amyloidogenic mutations. NMR experiments suggest that this phenomenon occurs, at least in part, through the transmission of long-range conformational effects to the interface between the two structural domains of the lysozyme protein. These results show that the use of antibodies can establish in a unique manner the link between the molecular properties of a given protein and its propensity to convert into amyloid fibrils. Indeed, the studies of lysozyme not only strongly support the involvement of partially unfolded species in the initiation of the aggregation events that lead to the formation of amyloid in clinical diseases, but also identify the global cooperativity of their structures as a key property that enables natural proteins to avoid aggregation [75].

\subsection{Elucidation of the mechanism of aggregation}

Fig. 1 indicates in schematic form the various types of monoclonal antibodies that could be generated to probe aspects of protein aggregation diseases. The use of a panel of antibodies could in principle allow the whole sequence of events that occur during the aggregation process to be deciphered. In the case of TTR for example, the two epitopes that are exposed upon the formation of the amyloidogenic intermediate (see above) are found to be accessible in the fibril

cAb-HuL6 stabilises the native state of the variant through conformational rearrangements at the interface between the two structural domains of the protein (see text). 
[51]. This finding suggests that these epitopes are not involved in the formation of the core of the fibrils but are rather exposed on their surface. It also indicates that no significant conformational rearrangements occur in this region of the protein during the association process. Monoclonal antibody fragments reacting with different epitopes of $\operatorname{PrP}^{C}$ have been reported to inhibit efficiently prion propagation in scrapie prion-infected neuroblasma cells [76]. The inhibitory effect was explained by the antibody binding to $\mathrm{PrP}^{\mathrm{C}}$ thereby preventing the docking of the $\mathrm{PrP}^{\mathrm{Sc}}$ template or a cofactor critical for the conversion of the $\operatorname{PrP}^{\mathrm{C}}$ into $\mathrm{PrP}^{\mathrm{Sc}}$ [76]. Identification of the epitope of these antibody fragments indicated that the 96-104 and 132-156 regions of the prion protein (PrP) are likely to be critical components of the $\mathrm{PrP}^{\mathrm{C}}-\mathrm{PrP}^{\mathrm{Sc}}$ interface.

\subsection{Elucidation of the mechanism of toxicity}

Although the link between amyloid formation and disease is now widely accepted, the specific nature of the pathogenic species and the mechanism by which they mediate their toxicity are still the subjects of intense debate. There is growing evidence that early intermediates in the aggregation process that leads to amyloid structures - even from proteins that are not associated with disease-are much more cytotoxic than the mature amyloid fibrils $[7,15,59]$. Moreover, the specific mechanism(s) by which these species appear to mediate their toxic effects is beginning to be understood (for a review see [7]). The availability of antibodies specific to small soluble aggregates (antibody 6 in Fig. 1) therefore enables the role of such species in protein aggregation diseases to be probed in detail $[61,77,78]$. Remarkably, the oligomer-specific generic antibodies have been reported to be capable of protecting cultured cells against the toxicity of aggregates derived from a variety of proteins [61]. This finding strongly supports the idea that small aggregates are cytotoxic and suggests that these species may share a common pathogenic mechanism, probably mediated by common features of their structures [61].

By using antibodies specific to small soluble aggregates, the presence of such aggregates has been identified in brain sections from transgenic mice models and from sufferers of Alzheimer's disease $[61,77,78]$. The ratio of the amount of this type of aggregate in AD-brains versus control brains has been estimated to be up to 70:1 [78]. Moreover, their distribution is significantly different from that of fibrillar amyloid deposits $[61,77]$, perhaps providing an explanation for the fact that the plaque load and the severity of the symptoms are not highly correlated [59]. Finally, in some transgenic mice, vaccination with $\mathrm{A} \beta$ has prevented the age dependent memory loss characteristic of such animals while only modestly decreasing the amyloid plaque burden, suggesting that the antibodies produced following the vaccination could specifically target the oligomeric species responsible for memory loss [79]. Even more remarkably, a single administration of a monoclonal antibody to $A \beta$ has recently been shown rapidly (within hours) to reverse memory impairment in certain learning and memory tasks in transgenic mouse models of Alzheimer's disease without any detectable alteration in the $A \beta$ burden, suggesting that this antibody also targets soluble $\mathrm{A} \beta$ species that are particularly toxic [80].

\section{Diagnostic and therapeutic reagents}

The use of antibodies and their fragments is not restricted to studies of the structures of the various species formed during fibril formation and the mechanism of aggregation, but in addition offers new opportunities for diagnosis and therapeutic reagents for the different types of amyloid diseases.

\subsection{Diagnostic reagents}

Variant Creutzfeldt-Jakob disease (vCJD) is thought to be linked with the consumption of infected beef from animals suffering from bovine spongiform encephalopathy (BSE). In order to prevent contaminated carcasses entering the human food chain, rapid diagnostic tests based on the post-mortem immunological detection of $\mathrm{PrP}^{\mathrm{Sc}}$ in livestock have been developed [81]. The tests that are commercially available at the present time are not based on the use of antibodies that are specific to $\operatorname{PrP}^{\mathrm{Sc}}$. They therefore involve a pre-treatment of the sample prior to measurement, to degrade the soluble $\operatorname{PrP}^{\mathrm{C}}$ molecules or denature the $\operatorname{PrP}^{\mathrm{Sc}}$ (see details in Textbox 2). Antibodies have, however, been produced that are reported to bind selectively to $\operatorname{PrP}^{\mathrm{Sc}}[52,53]$; if the specificity of these antibodies is confirmed they should provide a direct means of identifying $\mathrm{PrP}^{\mathrm{Sc}}$ in the presence of $\mathrm{PrP}^{\mathrm{C}}$. As mentioned above, a general feature of the amyloid diseases is the prolonged period of time before clinical manifestations of the disorder appear. During this preclinical phase, proteins are assumed to misfold, accumulate as aggregates and progressively compromise cellular and tissue function. Presymptomatic and minimally invasive diagnostic approaches are therefore crucial to enhance the chance of success of any possible interventional approach. It has been shown that $\mathrm{PrP}^{\mathrm{Sc}}$ could be detected in the tongue of a vCJD patient [82], at preclinical stages in tonsils of sheep infected with scrapie [83] and in human appendices [84], indicating that lymphoid tissue biopsies could in principle be used for early diagnosis of vCJD. In addition, efforts are currently made to develop tests that can detect $\mathrm{PrP}^{\mathrm{Sc}}$ in blood where its concentration is 100-1000 times lower than in the brain.

Antibodies may also prove useful for early diagnosis of Alzheimer's disease. After a peripheral administration of a monoclonal antibody to $\mathrm{A} \beta$ in mice, a rapid increase in plasma $A \beta$ was observed that is highly correlated with the amyloid burden in the brain [85]. If a similar phenomenon is observed in humans, such an antibody may be useful for quantifying brain amyloid burden in patients who have been diagnosed with Alzheimer's disease, or even known to be at 


\section{Diagnostic tests of BSE.}

Antibodies specific for $\mathrm{PrP}^{\mathrm{Sc}}$ are not yet commercially available; the diagnostic tests therefore involve specific pre-treatments to be able to distinguish $\operatorname{PrP}^{\mathrm{Sc}}$ from ubiquitous $\operatorname{PrP}^{\mathrm{C}}$. Two types of tests are currently used:

1. Tests based on the detection of protease resistant forms of PrP: These tests are based on the observation that the $\mathrm{C}$-terminal region of $\operatorname{PrP}$ (usually denoted as $\mathrm{PrP}^{27-30}$ ) is resistant to a treatment with the proteinase $\mathrm{K}$ in $\mathrm{PrP}^{\mathrm{Sc}}$ but not in $\mathrm{PrP}^{\mathrm{C}}$. Thus, the $\mathrm{PrP}^{\mathrm{C}}$ species is first eliminated from the sample by a proteolytic treatment. The abnormal protease-resistant form of $\operatorname{PrP}$ is then detected by an immunometric assay.

2. Conformation-dependent immunoassay: These tests are based on the use of an antibody that is specific to an epitope, which is exposed in $\mathrm{PrP}^{\mathrm{C}}$ but hidden in $\mathrm{PrP}^{\mathrm{Sc}}$. This epitope is, however, also exposed after denaturation of the $\mathrm{PrP}^{\mathrm{Sc}}$ by heat treatment in the presence of chemical denaturants. The sample is divided into two parts, one of which is denatured. In the untreated sample, the antibody allows the detection of only the $\mathrm{PrP}^{\mathrm{C}}$ species whereas in the denatured sample, it allows the detection of both $\mathrm{PrP}^{\mathrm{C}}$ and $\mathrm{PrP}^{\mathrm{Sc}}$. The amount of $\mathrm{PrP}^{\mathrm{Sc}}$ can therefore be determined by quantifying the relative binding of the monoclonal antibody to denatured and native samples.

risk of developing it. Finally, antibodies that bind to the generic epitope(s) of oligomeric aggregates or fibrils such as those described above $[61,70,71]$, may prove to be reagents able to diagnose the whole family of amyloid diseases.

\subsection{Therapeutic reagents}

Recent studies report the success of both active and passive vaccination approaches to slowing and/or reversing the aggregation process, and its pathological consequences, in mouse models of light chain amyloidosis [71], Alzheimer's disease [77,79,80,86-90] and mammalian prion diseases [76,91-93]. The molecular mechanisms by which antibodies act in a therapeutic manner are just beginning to be understood (for recent reviews see [94-99]) (Textbox 3). The favourable results with animal models led to an initial clinical trial, in which AD patients were injected with samples of aggregated $\mathrm{A} \beta$-peptide to elicit an immune response. Although some of the patients appeared to be benefiting significantly from the treatment [100], about $4 \%$ of the trial participants developed meningoencephalitis-like inflammation;

Textbox 3 this phenomenon then resulted in the discontinuation of the trial [101]. Many different antibodies are produced in response to active immunisation with an antigen, and it is possible that some of them exacerbate the neurodegenerative process rather than having beneficial effects. For example it has been recently reported that a specific monoclonal antibody can trigger rapid and extensive apoptosis in hippocampal and cerebellar neurons [102] or cerebral haemorrhage [103]. The mechanisms underlying the potentially adverse effects of amyloid immunotherapy are being very actively investigated and extensive research is under way to develop new vaccination strategies to enable beneficial effects to be achieved without undesirable side effects (for reviews see [94-99,104,105]). Passive immunisation with antibodies with predetermined effects on amyloid fibril formation/ clearance and toxicity represents an alternative strategy to avoid the potentially damaging side effects of active immunisation $[95,96,99,104,105]$. Sequences corresponding of the paratope (i.e. the region of the antibody reacting with the antigen) of such antibodies can be used as lead to the rational design of small-molecule drugs [106].

\section{Potential mechanisms of action of antibodies in mice models of Alzheimer's disease.}

- Peripheral sink: The anti-A $\beta$ antibodies bind to the circulating plasma $A \beta$-peptide, resulting in greater efflux from the brain as a result of the concentration gradient.

- Fibril breakdown: Some antibodies are able to cross the blood-brain barrier and attack amyloid plaques in the brain. The clearance of the plaques occurs through Fc-mediated phagocytosis by microglial cells or/and direct antibody-mediated dissaggregation of fibrils.

- Neutralisation of the "synaptotoxic" $A \beta$ species in the brain.

These mechanisms are not mutually exclusive and any number of them may act under a given set of circonstumances, with factors including the epitope, the isotype, and amyloid burden likely to influence the primary mean of action. 


\section{Conclusions and future prospects}

The main power of the antibody approach is that monoclonal antibodies can in principle be raised against any peptide or protein, and are very specific to the antigen against which they are raised, allowing the identification of different conformational states of proteins. Moreover, the breadth of specificity can be adjusted through judicious choice of antigens and screening procedures. This point is well illustrated by the fact that it is possible to generate monoclonal antibodies either against a generic epitope of mature amyloid fibrils or against an epitope specific to amyloid fibrils derived from a given protein. Another remarkable example is the demonstration that antibodies can be generated that can distinguish between small, soluble aggregates and the mature fibrils. Up to now, however, antibody studies directed at understanding amyloid deposition have only been carried out for diseaserelated peptides and proteins. Extension of its use to the much wider range of peptides and proteins that are unrelated to disease but which can form amyloid fibrils, as well as to specific mutant proteins associated with disease, will undoubtedly lead to further insights into the general mechanism of fibril formation.

Importantly for fundamental mechanistic studies, the biophysical properties of antibodies, such as their stability and affinity, can be adjusted to be compatible with the physicochemical conditions that are most appropriate to study the process of fibril formation in vitro. One way to achieve this is to use antibody engineering techniques, which associate in vitro-generated genetic diversity with selection procedures such as phage, ribosome or RNA display [107] to generate and screen for antibodies that are functional under highly denaturing conditions [108,109]. In this context, the heavychain camelid antibody fragments appear to be of particular interest. Camelids (camels, dromedaries and llamas) generate functional antibodies consisting only of two heavy chains; the latter also differ from the corresponding regions of conventional antibodies in that they lack the $\mathrm{CH} 1$ domain [110]. Since they are devoid of the light chains of conventional antibodies, the antigen binding site of these "heavychain" antibodies is limited to a single-domain, referred to as the $\mathrm{V}_{\mathrm{H}} \mathrm{H}$ domain. Following immunisation, recombinant $\mathrm{V}_{\mathrm{H}} \mathrm{Hs}$ can be isolated, and produced as soluble monomers in E. coli [111]. Biophysical studies have revealed that $\mathrm{V}_{\mathrm{H}} \mathrm{Hs}$ have a number of unique features compared to those of conventional antibody fragments, notably smaller size $\left(M_{\mathrm{r}} \sim 14,000\right)$, greater solubility and higher stability $[111,112]$. The latter property is of major importance since, as previously mentioned, significantly denaturating conditions generally need to be used to study the in vitro fibrillogenesis of a protein on a reasonable time scale. Finally, due to their small size, $\mathrm{V}_{\mathrm{H}} \mathrm{Hs}$ may cross the brain-blood barrier more readily to target plaques in the brain, hence making possible in vivo studies relevant to neurodegenerative diseases [113].

In summary, antibodies raised against a variety of states of a protein allow invaluable information to be obtained about the structures of the various species populated during amyloid fibril formation, and also on the mechanism of assembly that leads to the formation of amyloid deposits in vivo. The use of antibody technology can also give important clues about the nature of the cytotoxic species that are associated with the neurodegenerative diseases in particular. In addition, the use of monoclonal antibodies could be potentially extremely valuable for early diagnosis of amyloid diseases. Moreover, intensive research is being carried out to understand the mechanism of action of antibodies directed against amyloid fibrils or their precursors in vivo. Despite the side effects observed in the recent trial of human $A \beta$ immunisation, passive and even active immunisation against a wide range of protein misfolding diseases are undoubtedly highly promising therapeutic strategies that could result in effective clinical treatment in the not-too-distant future [94-99].

\section{Acknowledgements}

We would like to acknowledge the European Commission, the BBRSC, the Wellcome Trust and the Belgian Government, under the framework of the Interuniversity Attraction Poles, for their support of those parts of our own research that are described in this review. We thank Jesus Zurdo, Reto Bader, Mourad Tayebi, Natalià Carulla, and Filip Meersman for critical reading of the manuscript and for many helpful suggestions.

\section{References}

[1] S.E. Radford, C.M. Dobson, From computer simulations to human disease: emerging themes in protein folding, Cell. 97 (1999) 291-298.

[2] P. Tompa, Intrinsically unstructured proteins, Trends Biochem. Sci. 27 (2002) 527-533.

[3] R. Sitia, I. Braakman, Quality control in the endoplasmic reticulum protein factory, Nature 426 (2003) 891-894.

[4] A.L. Goldberg, Protein degradation and protection against misfolded or damaged proteins, Nature 426 (2003) 895-899.

[5] C.M. Dobson, Protein folding and misfolding, Nature 426 (2003) 884-890.

[6] P.J. Thomas, B.H. Qu, P.L. Pedersen, Defective protein folding as a basis of human disease, Trends Biochem. Sci. 20 (1995) 456-459.

[7] M. Stefani, C.M. Dobson, Protein aggregation and aggregate toxicity: new insights into protein folding, misfolding diseases and biological evolution, J. Mol. Med. 81 (2003) 678-699.

[8] V.N. Uversky, A.L. Fink, Conformational constraints for amyloid fibrillation: the importance of being unfolded, Biochim. Biophys. Acta 1698 (2004) 131-153.

[9] G. Merlini, V. Bellotti, Molecular mechanisms of amyloidosis, New Engl. J. Med. 349 (2003) 583-596.

[10] V.W. DeLaGarza, Pharmacologic treatment of Alzheimer's disease: an update, Am. Fam. Phys. 68 (2003) 1365-1372.

[11] L.E. Hebert, P.A. Scherr, J.L. Bienias, D.A. Benett, D.A. Evans, Alzheimer disease in the US population: prevalence estimates using the 2000 census, Arch. Neurol. 60 (2003) 1119-1122.

[12] J.I. Guijarro, M. Sunde, J.A. Jones, I.D. Campbell, C.M. Dobson, Amyloid fibril formation by an SH3 domain, Proc. Natl. Acad. Sci. USA 95 (1998) 4224-4228. 
[13] F. Chiti, P. Webster, N. Taddei, A. Clark, M. Stefani, G. Ramponi, et al., Designing conditions for in vitro formation of amyloid protofilaments and fibrils, Proc. Natl. Acad. Sci. USA 96 (1999) 3590-3594.

[14] S.V. Litvinovich, S.A. Brew, S. Aota, S.K. Akiyama, C. Haudenschild, K.C. Ingham, Formation of amyloid-like fibrils by self-association of a partially unfolded fibronectin type III module, J. Mol. Biol. 280 (1998) 245-258.

[15] M. Bucciantini, E. Giannoni, F. Chiti, F. Baroni, L. Formigli, J. Zurdo, N. Taddei, G. Ramponi, C.M. Dobson, M. Stefani, Inherent toxicity of aggregates implies a common mechanism for protein misfolding diseases, Nature 416 (2002) 507-511.

[16] C.M. Dobson, The structural basis of protein folding and its links with human disease, Philos, Trans. R. Soc. London B Biol. Sci. 356 (2001) 133-145.

[17] M. Sunde, C. Blake, The structure of amyloid fibrils by electron microscopy and X-ray diffraction, Adv. Prot. Chem. 50 (1997) 123159.

[18] D.R. Booth, M. Sunde, V. Bellotti, C.V. Robinson, W.L. Hutchinson, P.E. Fraser, et al., Instability, unfolding and aggregation of human lysozyme variants underlying amyloid fibrillogenesis, Nature 385 (1997) 787-793.

[19] W. Colon, J.W. Kelly, Partial denaturation of transthyretin is sufficient for amyloid fibril formation in vitro, Biochemistry 31 (1992) 86548660 .

[20] J.W. Kelly, The alternative conformations of amyloidogenic proteins and their multi-step assembly pathways, Curr. Opin. Struct. Biol. 8 (1998) 101-106.

[21] V.N. Uversky, J. Li, A.L. Fink, Evidence for a partially folded intermediate in alpha-synuclein fibril formation, J. Biol. Chem. 276 (2001) 10737-10744.

[22] R. Kayed, J. Bernhagen, N. Greenfield, K. Sweimeh, H. Brunner, W. Voelter, et al., Conformational transitions of islet amyloid polypeptide (IAPP) in amyloid formation in vitro, J. Mol. Biol. 287 (1999) 781-796.

[23] J.D. Harper, P.T. Lansbury Jr., Models of amyloid seeding in Alzheimer's disease and scrapie: mechanistic truths and physiological consequences of the time-dependent solubility of amyloid proteins, Annu. Rev. Biochem. 66 (1997) 385-407.

[24] J. Zurdo, Polypeptide models to understand protein misfolding and amyloid formation. Applications to protein design and therapeutics, Prot. Pept. Lett. (2004) (in press).

[25] L.A. Morozova-Roche, J. Zurdo, A. Spencer, W. Noppe, V. Receveur, D.B. Archer, et al., Amyloid fibril formation and seeding by wild-type human lysozyme and its disease-related mutational variants, J. Struct. Biol. 130 (2000) 339-351.

[26] M.R. Krebs, D.K. Wilkins, E.W. Chung, M.C. Pitkeathly, A.K. Chamberlain, J. Zurdo, et al., Formation and seeding of amyloid fibrils from wild-type hen lysozyme and a peptide fragment from the betadomain, J. Mol. Biol. 300 (2000) 541-549.

[27] D. Hamada, C.M. Dobson, A kinetic study of beta-lactoglobulin amyloid fibril formation promoted by urea, Prot. Sci. 11 (2002) 2417-2426.

[28] M. Dumoulin, A.M. Last, A. Desmyter, K. Decanniere, D. Canet, G. Larsson, A. Spencer, D.B. Archer, J. Sasse, S. Muyldermans, L. Wyns, C. Redfield, A. Matagne, C.V. Robinson, C.M. Dobson, A camelid antibody fragment inhibits the formation of amyloid fibrils by human lysozyme, Nature 424 (2003) 783-788.

[29] Y. Yonezawa, S. Tanaka, T. Kubota, K. Wakabayashi, K. Yutani, S. Fujiwara, An insight into the pathway of the amyloid fibril formation of hen egg white lysozyme obtained from a small-angle X-ray and neutron scattering study, J. Mol. Biol. 323 (2002) 237-251.

[30] A.K. Chamberlain, C.E. MacPhee, J. Zurdo, L.A. Morozova-Roche, H.A. Hill, C.M. Dobson, et al., Ultrastructural organization of amyloid fibrils by atomic force microscopy, Biophys. J. 79 (2000) 3282 3293.
[31] N.M. Kad, S.L. Myers, D.P. Smith, D.A. Smith, S.E. Radford, N.H. Thomson, Hierarchical assembly of beta2-microglobulin amyloid in vitro revealed by atomic force microscopy, J. Mol. Biol. 330 (2003) 785-7999.

[32] M. Bouchard, J. Zurdo, E.J. Nettleton, C.M. Dobson, C.V. Robinson, Formation of insulin amyloid fibrils followed by FTIR simultaneously with CD and electron microscopy, Prot. Sci. 9 (2000) 1960-1967.

[33] L. Nielsen, S. Frokjaer, J.F. Carpenter, J. Brange, Studies of the structure of insulin fibrils by Fourier transform infrared (FTIR) spectroscopy and electron microscopy, J. Pharm. Sci. 90 (2001) 29-37.

[34] J.L. Jimenez, J.I. Guijarro, E. Orlova, J. Zurdo, C.M. Dobson, M. Sunde, et al., Cryo-electron microscopy structure of an SH3 amyloid fibril and model of the molecular packing, EMBO J. 18 (1999) $815-821$.

[35] J.L. Jimenez, E.J. Nettleton, M. Bouchard, C.V. Robinson, C.M. Dobson, H.R. Saibil, The protofilament structure of insulin amyloid fibrils, Proc. Natl. Acad. Sci. USA 99 (2002) 9196-9201.

[36] M. Hoshino, H. Katou, Y. Hagihara, K. Hasegawa, H. Naiki, Y. Goto, Mapping the core of the beta(2)-microglobulin amyloid fibril by H/D exchange, Nat. Struct. Biol. 9 (2002) 332-336.

[37] I. Kheterpal, H.A. Lashuel, D.M. Hartley, T. Walz, P.T. Lansbury Jr., R. Wetzel, Abeta protofibrils possess a stable core structure resistant to hydrogen exchange, Biochemistry 42 (2003) 14092-14098.

[38] I. Kheterpal, S. Zhou, K.D. Cook, R. Wetzel, Abeta amyloid fibrils possess a core structure highly resistant to hydrogen exchange, Proc. Natl. Acad. Sci. USA 97 (2000) 13597-13601.

[39] A. Olofsson, J.H. Ippel, S.S. Wijmenga, E. Lundgren, A. Ohman, Probing solvent accessibility of transthyretin amyloid by solution NMR spectroscopy, J. Biol. Chem. 279 (2004) 5699-5707.

[40] P.T. Lansbury Jr., P.R. Costa, J.M. Griffiths, E.J. Simon, M. Auger, K.J. Halverson, et al., Structural model for the beta-amyloid fibril based on interstrand alignment of an antiparallel-sheet comprising a C-terminal peptide, Nat. Struct. Biol. 2 (1995) 990-998.

[41] A.T. Petkova, G. Buntkowsky, F. Dyda, R.D. Leapman, W.M. Yau, R. Tycko, Solid state NMR reveals a $\mathrm{pH}$-dependent antiparallel betasheet registry in fibrils formed by a beta-amyloid peptide, J. Mol. Biol. 335 (2004) 247-260.

[42] P. Polverino de Laureto, N. Taddei, E. Frare, C. Capanni, S. Costantini, J. Zurdo, F. Chiti, C.M. Dobson, A. Fontana, Protein aggregation and amyloid fibril formation by an $\mathrm{SH} 3$ domain probed by limited proteolysis, J. Mol. Biol. 334 (2003) 129-141.

[43] M. Monti, B.L. Garolla di Bard, G. Calloni, F. Chiti, A. Amoresano, G. Ramponi, P. Pucci, The regions of the sequence most exposed to the solvent within the amyloidogenic state of a protein initiate the aggregation process, J. Mol. Biol. 336 (2004) 253-262.

[44] F. Chiti, N. Taddei, M. Bucciantini, P. White, G. Ramponi, C.M. Dobson, Mutational analysis of the propensity for amyloid formation by a globular protein, EMBO J. 19 (2000) 1441-1449.

[45] T. Chiba, Y. Hagihara, T. Higurashi, K. Hasegawa, H. Naiki, Y. Goto, Amyloid fibril formation in the context of full-length protein: effects of proline mutations on the amyloid fibril formation of beta2microglobulin, J. Biol. Chem. 278 (2003) 47016-47024.

[46] A.D. Williams, E. Portelius, I. Kheterpal, J.T. Guo, K.D. Cook, Y. Xu, R. Wetzel, Mapping abeta amyloid fibril secondary structure using scanning proline mutagenesis, J. Mol. Biol. 335 (2004) 833-842.

[47] F. Eghiaian, J. Grosclaude, S. Lesceu, P. Debey, B. Doublet, E. Treguer, H. Rezaei, M. Knossow, Insight into the $\operatorname{PrP}^{C} \rightarrow \operatorname{PrP}^{S c}$ conversion from the structures of antibody-bound ovine prion scrapiesusceptibility variants, Proc. Natl. Acad. Sci. USA 101 (2004) 1025410259.

[48] M. Venturi, C. Hunte, Monoclonal antibodies for the structural analysis of the $\mathrm{Na}^{+} / \mathrm{H}^{+}$antiporter NhaA from Escherichia coli, Biochim. Biophys. Acta 1610 (2003) 46-50.

[49] R. Loris, I. Marianovsky, J. Lah, T. Laeremans, H. Engelberg-Kulka, G. Glaser, S. Muyldermans, L. Wyns, Crystal structure of the intrinsically flexible addiction antidote MazE, J. Biol. Chem. 278 (2003) 28252-28257. 
[50] C. Ostermeier, S. Iwata, B. Ludwig, H. Michel, Fv fragment-mediated crystallization of the membrane protein bacterial cytochrome $c$ oxidase, Nat. Struct. Biol. 2 (1995) 842-846.

[51] G. Goldsteins, H. Persson, K. Andersson, A. Olofsson, I. Dacklin, A. Edvinsson, et al., Exposure of cryptic epitopes on transthyretin only in amyloid and in amyloidogenic mutants, Proc. Natl. Acad. Sci. USA 96 (1999) 3108-3113.

[52] V. Curin Serbec, M. Bresjanac, M. Popovic, K. Pretnar Hartman, V. Galvani, R. Rupreht, M. Cernilec, T. Vranac, I. Hafner, R. Jerala, Monoclonal antibody against a peptide of human prion protein discriminates between Creutzfeldt-Jacob's disease-affected and normal brain tissue, J. Biol. Chem. 279 (2004) 3694-3698.

[53] E. Paramithiotis, M. Pinard, T. Lawton, S. LaBoissiere, V.L. Leathers, W.Q. Zou, L.A. Estey, J. Lamontagne, M.T. Lehto, L.H. Kondejewski, G.P. Francoeur, M. Papadopoulos, A. Haghighat, S.J. Spatz, M. Head, R. Will, J. Ironside, K. O'Rourke, Q. Tonelli, H.C. Ledebur, A. Chakrabartty, N.R. Cashman, A prion protein epitope selective for the pathologically misfolded conformation, Nat. Med. 9 (2003) 893899.

[54] R.A. Williamson, D. Peretz, C. Pinilla, H. Ball, R.B. Bastidas, R. Rozenshteyn, et al., Mapping the prion protein using recombinant antibodies, J. Virol. 72 (1998) 9413-9418.

[55] D. Peretz, R.A. Williamson, Y. Matsunaga, H. Serban, C. Pinilla, R.B. Bastidas, et al., A conformational transition at the $\mathrm{N}$ terminus of the prion protein features in formation of the scrapie isoform, J. Mol. Biol. 273 (1997) 614-622.

[56] Y. Matsunaga, D. Peretz, A. Williamson, D. Burton, I. Mehlhorn, D. Groth, F.E. Cohen, S.B. Prusiner, M.A. Baldwin, Cryptic epitopes in $\mathrm{N}$-terminally truncated prion protein are exposed in the full-length molecule: dependence of conformation on $\mathrm{pH}$, Proteins 44 (2001) 110-118.

[57] Z.F. Kanyo, K.M. Pan, R.A. Williamson, D.R. Burton, S.B. Prusiner, R.J. Fletterick, et al., Antibody binding defines a structure for an epitope that participates in the $\operatorname{PrP}^{\mathrm{C}} \rightarrow \operatorname{PrP}^{\mathrm{Sc}}$ conformational change, J. Mol. Biol. 293 (1999) 855-863.

[58] E. Leclerc, D. Peretz, H. Ball, L. Solforosi, G. Legname, J. Safar, A. Serban, S.B. Prusiner, D.R. Burton, R.A. Williamson, Conformation of $\mathrm{PrP}^{\mathrm{C}}$ on the cell surface as probed by antibodies, J. Mol. Biol. 326 (2003) 475-483.

[59] D.M. Walsh, I. Klyubin, J.V. Fadeeva, M.J. Rowan, D.J. Selkoe, Amyloid-beta oligomers: their production, toxicity and therapeutic inhibition, Biochem. Soc. Trans. 30 (2002) 552-557.

[60] W.L. Klein, Abeta toxicity in Alzheimer's disease: globular oligomers (ADDLs) as new vaccine and drug targets, Neurochem. Int. 41 (2002) 345-352.

[61] R. Kayed, E. Head, J.L. Thompson, T.M. McIntire, S.C. Milton, C.W. Cotman, C.G. Glabe, Common structure of soluble amyloid oligomers implies common mechanism of pathogenesis, Science 300 (2003) 486-489.

[62] P. Mangione, M. Sunde, S. Giorgetti, M. Stoppini, G. Esposito, L. Gianelli, L. Obici, L. Asti, A. Andreola, P. Viglino, G. Merlini, V. Bellotti, Amyloid fibrils derived from the apoliprotein A1 Leu74Ser variant contain elements of ordered helical structure, Prot. Sci. 10 (2001) 187-199.

[63] C.P. Jaroniec, C.E. MacPhee, V.S. Bajaj, M.T. McMahon, C.M. Dobson, R.G. Griffin, High-resolution molecular structure of a peptide in an amyloid fibril determined by magic angle spinning NMR spectroscopy, Proc. Natl. Acad. Sci. USA 101 (2004) 711-716.

[64] B. Solomon, R. Koppel, E. Hanan, T. Katzav, Monoclonal antibodies inhibit in vitro fibrillar aggregation of the Alzheimer beta-amyloid peptide, Proc. Natl. Acad. Sci. USA 93 (1996) 452-455.

[65] B. Solomon, R. Koppel, D. Frankel, E. Hanan-Aharon, Disaggregation of Alzheimer beta-amyloid by site-directed mAb, Proc. Natl. Acad. Sci. USA 94 (1997) 4109-4112.

[66] D. Frenkel, O. Katz, B. Solomon, Immunization against Alzheimer's beta-amyloid plaques via EFRH phage administration, Proc. Natl. Acad. Sci. USA 97 (2000) 11455-11459.
[67] J. McLaurin, R. Cecal, M.E. Kierstead, X. Tian, A.L. Phinney, M. Manea, J.E. French, M.H. Lambermon, A.A. Darabie, M.E. Brown, C. Janus, M.A. Chishti, P. Horne, D. Westaway, P.E. Fraser, H.T. Mount, M. Przybylski, P. St George-Hyslop, Therapeutically effective antibodies against amyloid-beta peptide target amyloid-beta residues 4-10 and inhibit cytotoxicity and fibrillogenesis, Nat. Med. 8 (2002) 1263-1269.

[68] A.T. Petkova, Y. Ishii, J.J. Balbach, O.N. Antzutkin, R.D. Leapman, F. Delaglio, R. Tycko, A structural model for Alzheimer's betaamyloid fibrils based on experimental constraints from solid state NMR, Proc. Natl. Acad. Sci. USA 99 (2002) 16742-16747.

[69] S. Emadi, R. Liu, B. Yuan, P. Schulz, C. McAllister, Y. Lyubchenko, A. Messer, M.R. Sierks, Inhibiting aggregation of alpha-synuclein with human single chain antibody fragments, Biochemistry 43 (2004) 2871-2878

[70] B. O'Nuallain, R. Wetzel, Conformational Abs recognizing a generic amyloid fibril epitope, Proc. Natl. Acad. Sci. USA 99 (2002) 14851490.

[71] R. Hrncic, J. Wall, D.A. Wolfenbarger, C.L. Murphy, M. Schell, D.T. Weiss, et al., Antibody-mediated resolution of light chainassociated amyloid deposits, Am. J. Pathol. 157 (2000) 1239-1246.

[72] D. Thompson, M.B. Pepys, I. Tickle, S. Wood, The structures of crystalline complexes of human serum amyloid $\mathrm{P}$ component with its carbohydrate ligand, the cyclic pyruvate acetal of galactose, J. Mol. Biol. 320 (2002) 1081-1086.

[73] M. Przybylski, V. Schnaible, J. Kast, S. Bohler, J. Michels, A. Wattenberg, et al., Approaches to the characterisation of tertiary and supramolecular protein structures by combination of protein chemistry and mass spectrometry, in: W. Ens (Ed.), New Methods for the Study of Biomolecular Complexes, Kluwer Academic Publishers, Amsterdam, 1998, pp. 17-43.

[74] E. Hanan, O. Goren, M. Eshkenazy, B. Solomon, Immunomodulation of the human prion peptide 106-126 aggregation, Biochem. Biophys. Res. Commun. 280 (2001) 115-120.

[75] C.M. Dobson, Protein misfolding, evolution and disease, Trends Biochem. Sci. 24 (1999) 329-332.

[76] D. Peretz, R.A. Williamson, K. Kaneko, J. Vergara, E. Leclerc, G. Schmitt-Ulms, I.R. Mehlhorn, G. Legname, M.R. Wormald, P.M. Rudd, R.A. Dwek, D.R. Burton, S.B. Prusiner, Antibodies inhibit prion propagation and clear cell cultures of prion infectivity, Nature 412 (2001) 739-743.

[77] M.P. Lambert, K.L. Viola, B.A. Chromy, L. Chang, T.E. Morgan, J. Yu, D.L. Venton, G.A. Krafft, C.E. Finch, W.L. Klein, Vaccination with soluble Abeta oligomers generates toxicity-neutralizing antibodies, J. Neurochem. 79 (2001) 595-605.

[78] Y. Gong, L. Chang, K.L. Viola, P.N. Lacor, M.P. Lambert, C.E. Finch, G.A. Krafft, W.L. Klein, Alzheimer's disease-affected brain: presence of oligomeric A beta ligands (ADDLs) suggests a molecular basis for reversible memory loss, Proc. Natl. Acad. Sci. USA 100 (2003) 10417-10422.

[79] D. Morgan, D.M. Diamond, P.E. Gottschall, K.E. Ugen, C. Dickey, J. Hardy, et al., A beta peptide vaccination prevents memory loss in an animal model of Alzheimer's disease, Nature 408 (2000) 982-985.

[80] J.C. Dodart, K.R. Bales, K.S. Gannon, S.J. Greene, R.B. DeMattos, C. Mathis, C.A. DeLong, S. Wu, X. Wu, D.M. Holtzman, S.M. Paul, Immunization reverses memory deficits without reducing brain Abeta burden in Alzheimer's disease model, Nat. Neurosci. 5 (2002) 452457.

[81] E. Kubler, B. Oesch, A.J. Raeber, Diagnosis of prion diseases, Br. Med. Bull. 66 (2003) 267-279.

[82] A.F. Hill, M. Zeidler, J. Ironside, J. Collinge, Diagnosis of new variant Creutzfeldt-Jakob disease by tonsil biopsy, Lancet 349 (1997) 99-100.

[83] B.E. Schreuder, L.J. Van Keulen, M.E. Vromans, J.P. Langeveld, M.A. Smits, Tonsillar biopsy and $\mathrm{PrP}^{\mathrm{Sc}}$ detection in the preclinical diagnosis of scrapie, Vet. Rec. 142 (1998) 564-568. 
[84] D.A. Hilton, E. Fathers, P. Edwards, J.W. Ironside, J. Zajicek, Prion immunureactivity in appendix before clinical onset of variant Creutzfeldt-Jacob disease, Lancet 352 (1998) 703-704.

[85] R.B. DeMattos, K.R. Bales, D.J. Cummins, S.M. Paul, D.M. Holtzman, Brain to plasma amyloid-beta efflux: a measure of brain amyloid burden in a mouse model of Alzheimer's disease, Science 295 (2002) 2264-2267.

[86] F. Bard, C. Cannon, R. Barbour, R.L. Burke, D. Games, H. Grajeda, et al., Peripherally administered antibodies against amyloid betapeptide enter the central nervous system and reduce pathology in a mouse model of Alzheimer disease, Nat. Med. 6 (2000) 916-919.

[87] F. Bard, R. Barbour, C. Cannon, R. Carretto, M. Fox, D. Games, T. Guido, K. Hoenow, K. Hu, K. Johnson-Wood, K. Khan, D. Kholodenko, C. Lee, M. Lee, R. Motter, M. Nguyen, A. Reed, D. Schenk, P. Tang, N. Vasquez, P. Seubert, T. Yednock, Epitope and isotype specificities of antibodies to beta-amyloid peptide for protection against Alzheimer's disease-like neuropathology, Proc. Natl. Acad. Sci. USA 100 (2003) 2023-2028.

[88] D. Schenk, R. Barbour, W. Dunn, G. Gordon, H. Grajeda, T. Guido, et al., Immunization with amyloid-beta attenuates Alzheimer-diseaselike pathology in the PDAPP mouse, Nature 400 (1999) 173-177.

[89] C. Janus, J. Pearson, J. McLaurin, P.M. Mathews, Y. Jiang, S.D. Schmidt, et al., A beta peptide immunization reduces behavioural impairment and plaques in a model of Alzheimer's disease, Nature 408 (2000) 979-982.

[90] D.M. Wilcock, A. Rojiani, A. Rosenthal, G. Levkowitz, S. Subbarao, J. Alamed, D. Wilson, N. Wilson, M.J. Freeman, M.N. Gordon, D. Morgan, Passive amyloid immunotherapy clears amyloid and transiently activates microglia in a transgenic mouse model of amyloid deposition, J. Neurosci. 24 (2004) 6144-6151.

[91] F.L. Heppner, C. Musahl, I. Arrighi, M.A. Klein, T. Rulicke, B. Oesch, R.M. Zinkernagel, U. Kalinke, A. Aguzzi, Prevention of scrapie pathogenesis by transgenic expression of anti-prion protein antibodies, Science 294 (2001) 178-182.

[92] E.M. Sigurdsson, D.R. Brown, M. Daniels, R.J. Kascsak, R. Kascsak, R. Carp, H.C. Meeker, B. Frangione, T. Wisniewski, Immunization delays the onset of prion disease in mice, Am. J. Pathol. 161 (2002) 13-17.

[93] A.R. White, P. Enever, M. Tayebi, R. Mushens, J. Linehan, S. Brandner, D. Anstee, J. Collinge, S. Hawke, Monoclonal antibodies inhibit prion replication and delay the development of prion disease, Nature 422 (2003) 80-83.

[94] D. Schenk, Amyloid-beta immunotherapy for Alzheimer's disease: the end of the beginning, Nat. Rev. Neurosci. 3 (2002) 824-828.

[95] J.C. Dodart, K.R. Bales, S.M. Paul, Immunotherapy for Alzheimer's disease: will vaccination work? Trends Mol. Med. 9 (2003) 85-87.

[96] R.C. Dodel, H. Hampel, H. Du, Immunotherapy for Alzheimer's disease, Lancet Neurol. 2 (2003) 215-220.

[97] E.M. Sigurdsson, T. Wisniewski, B. Frangione, A safer vaccine for Alzheimer's disease? Neurobiol. Aging 23 (2002) 1001-1008.

[98] A.R. White, S.H. Hawke, Immunotherapy as a therapeutic treatment for neurodegenerative disorders, J. Neurochem. 87 (2003) 801-808.

[99] D.S. Gelinas, K. DaSilva, D. Fenili, P. St. George Hyslop, J. McLaurin, Immunotherapy for Alzheimer's disease, Proc. Natl. Acad. Sci. USA 101 (Suppl. 2) (2004) 14657-14662.

[100] C. Hock, U. Konietzko, J.R. Streffer, J. Tracy, A. Signorell, B. MullerTillmanns, U. Lemke, K. Henke, E. Moritz, E. Garcia, M.A. Wollmer, D. Umbricht, D.J. de Quervain, M. Hofmann, A. Maddalena, A. Papassotiropoulos, R.M. Nitsch, Antibodies against beta-amyloid slow cognitive decline in Alzheimer's disease, Neuron 38 (2003) $547-554$.
[101] E. Check, Nerve inflamation halts trial for Alzheimer's drug, Nature 415 (2002) 462.

[102] L. Solforosi, J.R. Criado, D.B. McGavern, S. Wirz, M. SanchezAlvarez, S. Sugama, L.A. DeGiorgio, B.T. Volpe, E. Wiseman, E. Masliah, D. Gilden, M.B. Oldstone, B. Conti, R.A. Williamson, Cross-linking cellular prion protein triggers neuronal apoptosis in vivo, Science 303 (2004) 1514-1516.

[103] M. Pfeifer, S. Boncristiano, L. Bondolfi, A. Stalder, T. Deller, M. Staufenbiel, P.M. Mathews, M. Jucker, Cerebral hemorrhage after passive anti-Abeta immunotherapy, Science 298 (2002) 1379.

[104] S.M. Greenberg, B.J. Bacskai, B.T. Hyman, Alzheimer diseases double-edged vaccine, Nat. Med. 9 (2003) 389-390.

[105] A. Monsonego, H.L. Weiner, Immunotherapeutic approaches to Alzheimer's disease, Science 302 (2003) 834-838.

[106] C. Monnet, D. Laune, J. Laroche-Traineau, M. Biard-Piechaczyk, L. Briant, C. Bes, et al., Synthetic peptides derived from the variable regions of an anti-CD4 monoclonal antibody bind to CD4 and inhibit HIV-1 promoter activation in virus-infected cells, J. Biol. Chem. 274 (1999) 3789-3796.

[107] P. Amstutz, P. Forrer, C. Zahnd, A. Pluckthun, In vitro display technologies: novel developments and applications, Curr. Opin. Biotechnol. 12 (2001) 400-405.

[108] D. Degl'Innocenti, N. Taddei, M. Ramazzotti, M. Stefani, F. Chiti, G. Ramponi, Selection of antibody fragments specific for an alphahelix region of acylphosphatase, J. Mol. Recognit. 17 (2004) 62-66.

[109] B. Bose, D.A. Chugh, M. Kala, S.K. Acharya, N. Khanna, S. Sinha, Characterization and molecular modeling of a highly stable antiHepatitis B surface antigen scFv, Mol. Immunol. 40 (2003) 617-631.

[110] C. Hamers-Casterman, T. Atarhouch, S. Muyldermans, G. Robinson, C. Hamers, E.B. Songa, et al., Naturally occurring antibodies devoid of light chains, Nature 363 (1993) 446-448.

[111] S. Muyldermans, Single domain camel antibodies: current status, J. Biotechnol. 74 (2001) 277-302.

[112] M. Dumoulin, K. Conrath, A. Van Meirhaeghe, F. Meersman, K. Heremans, L.G. Frenken, S. Muyldermans, L. Wyns, A. Matagne, Singledomain antibody fragments with high conformational stability, Prot. Sci. 11 (2002) 500-515.

[113] A. Muruganandam, J. Tanha, S. Narang, D. Stanimirovic, Selection of phage-displayed llama single-domain antibodies that transmigrate across human blood-brain barrier endothelium, FASEB J. 16 (2002) 240-242.

[114] M.B. Pepys, P.N. Hawkins, D.R. Booth, D.M. Vigushin, G.A. Tennent, A.K. Soutar, et al., Human lysozyme gene mutations cause hereditary systemic amyloidosis, Nature 362 (1993) 553-557.

[115] S. Valleix, S. Drunat, J.B. Philit, D. Adoue, J.C. Piette, D. Droz, B. MacGregor, D. Canet, M. Delpech, G. Grateau, Hereditary renal amyloidosis caused by a new variant lysozyme W64R in a French family, Kidney Int. 61 (2002) 907-912.

[116] M. Yazaki, S.A. Farrell, M.D. Benson, A novel lysozyme mutation Phe57Ile associated with hereditary renal amyloidosis, Kidney Int. 63 (2003) 1652-1657.

[117] D. Canet, A.M. Last, P. Tito, M. Sunde, A. Spencer, D.B. Archer, C. Redfield, C.V. Robinson, C.M. Dobson, Local cooperativity in the unfolding of an amyloidogenic variant of human lysozyme, Nat. Struct. Biol. 9 (2002) 308-315.

[118] A.K. Chamberlain, V. Receveur, A. Spencer, C. Redfield, C.M. Dobson, Characterization of the structure and dynamics of amyloidogenic variants of human lysozyme by NMR spectroscopy, Prot. Sci. 10 (2001) 2525-2530. 